\title{
Growth after gut resection for Crohn's disease
}

\author{
B I McLain, P M Davidson, K B Stokes, S W Beasley
}

\begin{abstract}
Seventeen children underwent 19 bowel resections as part of their management of Crohn's disease. Thirteen children had evidence of retardation of linear growth preoperatively, of whom 12 exhibited catch up growth, crossing at least one centile band, after resection. Seven of the 12 showed early signs of puberty at the time of resection and one child was regarded as being fully pubertal. All children were symptomatic before their surgery; at one year 11 were asymptomatic and three others were substantially improved.

Surgical resection of localised Crohn's disease, followed by adequate nutritional support has lead to catch up growth and a prolonged symptom free period in most of our patients and this was not limited by their age or stage of puberty.
\end{abstract}

The effect on growth of surgical resection of diseased bowel in Crohn's disease is unclear. Homer et al reported growth catch up in only two of 37 children, of whom 14 were growth retarded at the time of resection, and concluded that catch up growth occurs infrequently after surgery, and only in children operated on before puberty. ${ }^{1}$ Guttman reported catch up growth in three of six children with growth failure $(<3$ rd centile), ${ }^{2}$ and Wesson and Shandling demonstrated some catch up in 10 of $15 .^{3}$ Frey et al found improved growth centiles in six of seven prepubertal children and in three of five postpubertal children who had a partial or total colectomy. ${ }^{4}$

This study was undertaken to assess the effect of gut resection on the growth, sexual development, and symptomatology of children with Crohn's disease.

\section{Patients and methods}

During the period 1971 to 1987,72 children under 16 years of age with Crohn's disease treated at the Royal Children's Hospital, were reviewed retrospectively. The patients were identified from review of pathology records and the hospital medical records index of discharge diagnoses. The diagnosis of Crohn's disease was confirmed by the pathological findings of transmural inflammation, granulomata, and crypt abscesses in biopsy specimens. In 52 of the 72 there were associated radiological findings compatible with Crohn's disease.

Seventeen of the 72 children had surgical resections as part of their management. Two children required two separate resections. In each patient, the diagnosis was confirmed on histological examination of the resected bowel.

Changes in growth, sexual development, and symptoms after surgery were analysed. Heights before and after surgery were recorded according to the percentile bands within which they lay. Standard centile charts of Dr H C Stuart (Boston, Massachusetts, USA) were used.

\section{Results}

Seventeen patients underwent laparotomy and bowel resection as part of their management of Crohn's disease. Table 1 summarises their sex, age at diagnosis, age at surgery, indications for surgery, and site of resection.

In two patients laparotomy was undertaken to establish the diagnosis before colonoscopy became routine. A stricture was identified radiologically after a period of intensive medical treatment in five. Three patients presented with an abdominal mass that failed to resolve with conservative treatment and five had persistent symptoms, despite medical treatment and
Royal Children's Hospital, Melbourne, Department of Gastroenterology B I McLain

Department of General Surgery

P M Davidson

K B Stokes

S W Beasley

Correspondence to:

Dr K B Stokes,

Department of

General Surgery,

Royal Children's Hospital,

Flemington Road,

Parkville, Victoria 3052 ,

Australia.

Accepted 26 February 1990
Table 1 Demographic details of 17 children with Crohn's disease who underwent resection

\begin{tabular}{|c|c|c|c|c|c|}
\hline Case No & Sex & $\begin{array}{l}\text { Age at diagnosis } \\
\text { (years) }\end{array}$ & $\begin{array}{l}\text { Age at surgery } \\
\text { (years) }\end{array}$ & Indication for surgery & Resection site \\
\hline $\begin{array}{r}1 \\
2 \\
3 \\
4 \\
5 \\
6 \\
7 \\
8 \\
9 \\
10 \\
11 \\
12\end{array}$ & $\begin{array}{l}\mathbf{F} \\
\mathbf{F} \\
\mathbf{M} \\
\mathbf{F} \\
\mathbf{F} \\
\mathbf{M} \\
\mathbf{F} \\
\mathbf{F} \\
\mathbf{F} \\
\mathbf{M} \\
\mathbf{M}\end{array}$ & $\begin{array}{l}13 \cdot 7 \\
12 \cdot 0 \\
13 \cdot 0 \\
14 \cdot 0 \\
12 \cdot 2 \\
12 \cdot 6 \\
10 \cdot 2 \\
13 \cdot 3 \\
12 \cdot 3 \\
12 \cdot 0 \\
11 \cdot 8 \\
13 \cdot 1\end{array}$ & $\begin{array}{l}13 \cdot 7 \\
12 \cdot 1 \\
17 \cdot 3 \\
14 \cdot 7 \\
14 \cdot 7 \\
14 \cdot 5 \\
13 \cdot 4 \\
13 \cdot 3 \\
12 \cdot 8 \\
16 \cdot 5 \\
17 \cdot 3 \\
13 \cdot 1\end{array}$ & $\begin{array}{l}\text { Diagnosis } \\
\text { Stricture } \\
\text { Stricture } \\
\text { Failure of medical treatment } \\
\text { Mass } \\
\text { Stricture } \\
\text { Failure of medical treatment } \\
\text { Diagnosis } \\
\text { Perianal sepsis } \\
\text { Stricture } \\
\text { Failure of medical treatment } \\
\text { Perforation }\end{array}$ & $\begin{array}{l}\text { Ileum/right colon } \\
\text { Ileum/right colon } \\
\text { Ileum/caecum } \\
\text { Jejunum } \\
\text { Ileum } \\
\text { Ileum } \\
\text { Ileum/caecum } \\
\text { Ileum/right colon } \\
\text { Ileum+stoma } \\
\text { Ileum } \\
\text { Ileum/right colon } \\
\text { Ileum }\end{array}$ \\
\hline $\begin{array}{l}13 \\
14 \\
15\end{array}$ & $\begin{array}{l}\mathbf{M} \\
\mathbf{F} \\
\mathbf{M}\end{array}$ & $\begin{array}{r}12 \cdot 3 \\
12 \cdot 3 \\
5 \cdot 3\end{array}$ & $\begin{array}{r}14 \cdot 1 \\
16 \cdot 3 \\
\text { (1) } 8 \cdot 1 \\
\text { (2) } 9 \cdot 2\end{array}$ & $\begin{array}{l}\text { Stricture } \\
\text { Fistula } \\
\text { Failure of medical treatment } \\
\text { Discharge }\end{array}$ & $\begin{array}{l}\text { Ileum } \\
\text { Ileum/right colon } \\
\text { Subtotal colon } \\
\text { Rectum stump }\end{array}$ \\
\hline $\begin{array}{l}16 \\
17\end{array}$ & $\begin{array}{l}\mathbf{M} \\
\mathbf{M}\end{array}$ & $\begin{array}{l}12 \cdot 4 \\
11 \cdot 2\end{array}$ & $\begin{array}{l}13 \cdot 3 \\
13 \cdot 2\end{array}$ & $\begin{array}{l}\text { Failure of medical treatment } \\
\text { Failure of medical treatment }\end{array}$ & $\begin{array}{l}\text { Ileum/right colon } \\
\text { Ileum/right colon }\end{array}$ \\
\hline
\end{tabular}


radiologically proved localised disease. The child with perianal disease had a diverting ileostomy, as well as a resection, to allow perianal sepsis to settle.

The child who had a subtotal colectomy had an ileostomy and later an abdominoperineal resection of the rectal stump.

In all but two cases, the anastomosed ends at the margins of resection were free of macroscopic involvement, and all severely involved bowel was resected. The two exceptions were one child who presented with a spontaneous perforation, and a second child who had an exploratory laparotomy. Both had preservation of bowel with active disease. These children (cases 8 and 12) remained symptomatic.

Apart from the two children who had a laparotomy and resection to establish the diagnosis, resection was carried out after a period of medical treatment in all patients. This included a course of prednisolone (2-3 mg/kg/day) for four to six weeks, reducing gradually over a further four to eight weeks to a low maintenance dose of $2-5 \mathrm{mg} /$ day or discontinuing if appropriate. Sulphasalazine was introduced when prednisolone dose was reduced. Three patients received metronidazole on a regular basis. No patient had azathioprine before surgery. None had prolonged parenteral or elemental enteral feeding before surgery, although two received a short period of parenteral nutrition to improve their nutritional state preoperatively.

The extent of follow up after surgery ranged from 15 months to eight years.

Table 2 Symptoms before and one year after 19 resections in 17 children

\begin{tabular}{lll}
\hline & Preoperatively & $\begin{array}{l}\text { One year } \\
\text { postoperatively }\end{array}$ \\
\hline Asymptomatic and well & Nil & 11 \\
Recurrent abdominal pain & 19 & 5 \\
Anorexia & 10 & 2 \\
Diarrhoea (>3 stools/day) & 7 & 1 \\
Fatigue & 6 & 3 \\
Perianal disease & 4 & 1 \\
Vomiting & 4 & 1 \\
Urinary tract infection & 1 & 0 \\
Arthritis & 1 & 0 \\
Rectal discharge & $1^{*}$ & $1 \dagger$ \\
\hline
\end{tabular}

*Reason for second resection; fafter first resection.

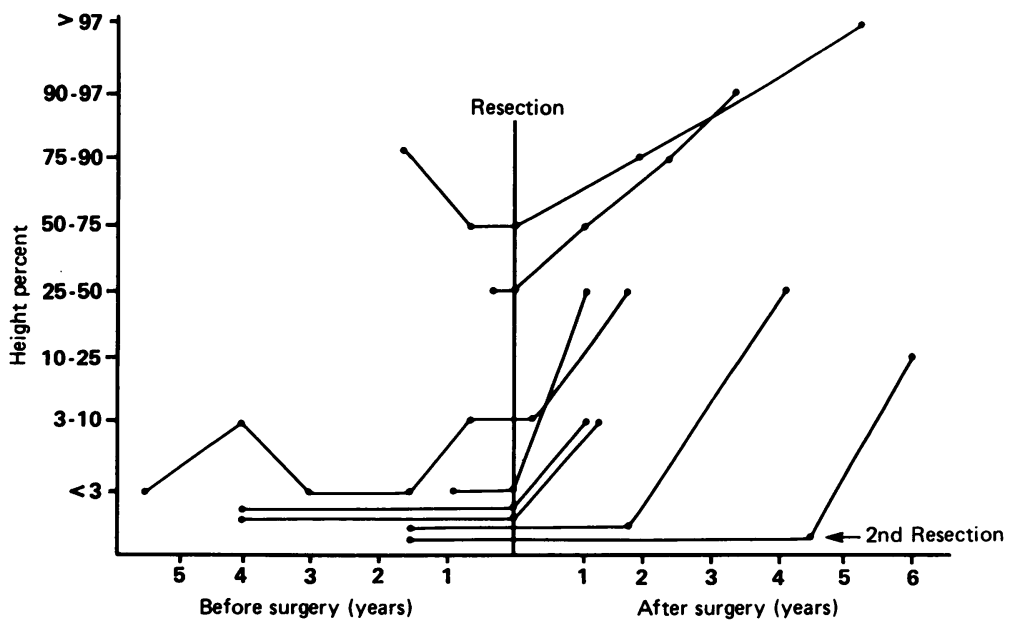

Figure 1 Height centile bands before and after resection in those children with major improvements in growth.
There were few complications of surgery. Both children with ileostomies had problems with recurrent prolapse of the ileum, one child had a wound abscess, two children subsequently required surgery for division of adhesions, and one child had chronic diarrhoea from bile salt malabsorption, treated successfully with cholestyramine.

\section{SYMPTOM OUTCOME}

Symptoms before, and one year after, resection are shown in table 2 . All patients were unwell and symptomatic with recurrent abdominal pain, in combination with at least one other symptom before resection.

In 11 children resection led to complete relief of symptoms for a minimum of one year after surgery. For six of these children it is now more than three years after surgery and they remain well. One child developed mild abdominal pain and fatigue at two years and another suffered a major relapse and new radiological evidence of disease 2.5 years after surgery. Three children were substantially improved by their operation but still had minor residual symptoms at one year. One child (case 15) became symptom free after resection of his rectal stump.

Five children gained no improvement after surgery, or improved for less than one year. One child (case 12) became symptom free after a second resection.

\section{GROWTH VARIABLES}

The effect of resection on height growth is shown in fig 1 and 2. Two children with insufficient growth data are not included. Seven children were below the 3rd centile at the time of resection. Four other children had fallen from previously attained centiles in the period before surgery, showing evidence of growth failure by stagnation in their linear growth. Six children had growth spurts that crossed two or three centile bands after surgery (fig 1). Two other children were well below the 3rd centile at surgery, yet had substantial growth spurts but only rose one centile band. Figure 2 shows another four children who had increases in growth that crossed one centile band. Case 4 remained below the 3 rd centile but did achieve some catch up growth before again becoming symptomatic. Case 8 did poorly after operation with limited subsequent linear growth eventually falling in her height centile. The final child maintained his previous normal centile.

\section{PUBERTY}

Seven out of 12 children with growth improvement after surgery showed evidence of puberty at the time of resection. Five of these were premenarcheal girls (aged 13-17 years) who exhibited breast enlargement and pubic hair (grade III on Tanner's sexual maturation rating (SMR)) at the time of resection. Menarche started two to 12 months after resection in these five girls. One of the two boys had early testicular and penile enlargement (SMR grade II), 


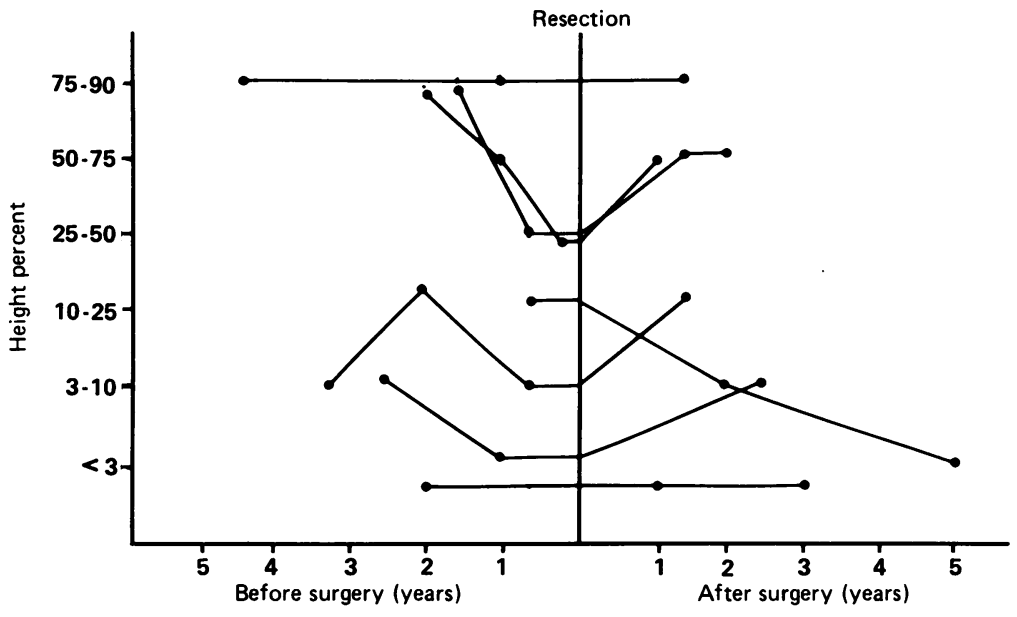

Figure 2 Height centile bands before and after resection in those children with either minimal or no improvement in growth.

while the other was regarded as being fully pubertal (grade V) at age 17 years. The other five children who showed increases in height centiles were prepubertal at resection.

\section{Discussion}

Many children with Crohn's disease are growth retarded. ${ }^{1-3}$ The reasons for this are numerous but one factor appears to be poor nutritional intake, ${ }^{5}$ exacerbated by increased nutritional requirements, increased intestinal losses and malabsorption. ${ }^{6}$

Growth failure may be reversed by supplementary enteral or parenteral feeding, ${ }^{7-9}$ but this usually entails a significant change in lifestyle that may be unacceptable to the adolescent, and is limited by their symptoms. Nutrition alone does not lead to sustained remission of symptoms and some patients with poorly controlled or severe disease will remain growth retarded.

The role and effects of gut resection in growth retarded children with Crohn's disease are controversial. ${ }^{1-3}$ Previous studies have made contradictory observations, resulting in conflicting conclusions as to the effect of resection on growth. Homer et al demonstrated catch up growth in only two of 37 children, ${ }^{1}$ whereas Frey et al found improvement in six of seven, including three of five postpubertal children. ${ }^{4}$

In the series described here, of the 17 children who had resection of localised disease, 12 showed catch up growth and six crossed at least two standard percentile bands. The differences between the findings of our study and the Boston study ${ }^{1}$ may relate to the different decades reviewed (1948-74 compared with 1971-88) in that it has been only in the last 15 years that the importance of a high energy and good quality protein intake in the treatment of growth failure in Crohn's disease has been recognised. ${ }^{4}$ Such a diet is often difficult to achieve in the preoperative period, especially when vomiting, anorexia, and abdominal pain are major symptoms. Postoperatively, when the child is asymptomatic, such a diet is easier to sustain.

Catch up growth will occur only when intervention is instituted before epiphyseal closure. ${ }^{5}$ Clearly, though, this may occur late in children with Crohn's disease as many of them have delayed onset of puberty (two children with substantial growth spurts were 17 years old at the time of resection). In our experience, catch up growth is not limited by the stage of puberty.

A prolonged symptom free period after resection was enjoyed by $70 \%$ of children. They experienced relatively normal adolescence and schooling without the shackles of a chronic debilitating illness.

If the child with Crohn's disease, complicated by absolute or relative growth failure, can be helped by a combination of medical and nutritional support with acceptable changes in lifestyle and normal schooling, that is clearly the preferred option. If this cannot be achieved, and disease remains localised, resection in combination with nutritional support postoperatively would appear to have a beneficial effect on growth and symptomatology even if puberty has already commenced.

The authors would like to thank Dr G L Barnes, Dr A L Smith and Dr D J S Cameron for allowing us to report on their patients. Dr McLain is in receipt of a Clinical Research Fellowship from the Royal Children's Hospital Research Foundation.

1 Homer DR, Grand RJ, Coldny AH. Growth, course and prognosis after surgery for Crohn's disease in children and prognosis after surgery for Crohn's disease

2 Guttman FM. Granulomatous enterocolitis in childhood and adolescence. I Pediatr Surg 1974;9:115-21.

3 Wesson DR, Shandling B. Results of bowel resection for Crohn's disease in the young. $\mathcal{F}$ Pediatr Surg 1981;16: 449-52.

4 Frey CF, Weaver DK, Arbor A. Colectomy in children with ulcerative and granulomatous colitis. Arch Surg 1972;104 416-23.

5 Kelts DG, Grand RJ, Shen G, Watkins JB, Werlin SL, Boehme C. Nutritional basis of growth failure in children and adolescents with Crohn's disease. Gastroenterology 1979;76:720-7.

6 Rosenthal SR, Snyder JD, Hendricks KM, Walker WA Growth failure and inflammatory bowel disease: approach to treatment of a complicated adolescent problem. Pediatto treatment of a comp
rics 1983;72:481-90.

7 Morin CL, Roulet M, Roy CC, Weber A. Continuous elemental enteral feeding alimentation in children with Crohn's disease and growth failure. Gastroenterology 1980; 79:1205-10.

8 Kirschner BS, Klich JR, Kalman SS, De Favaro MV Rosenberg IH. Reversal of growth retardation in Crohn's disease with therapy emphasizing oral nutritional restitution. Gastroenterology 1981;80:10-5

9 Belli DC, Seidman E, Bouthillier L, et al. Chronic intermittent elemental diet improves growth failure in children with Crohn's disease. Gastroenterology 1988;94:602-10. 